\title{
Economic Importance of Bacillus Thurnigiens is bacterium for Bio Prospecting: A Review
}

\author{
Asfaw Tora Kacho* \\ College of Natural and Computational ScienceDepartment of Biology, Wolaita Soddo University, Ethiopia. \\ *Corresponding Author: Asfaw Tora Kacho, College of Natural and Computational Science \\ Department of Biology, Wolaita Soddo University, Ethiopia
}

\begin{abstract}
:
Background: Bacillus thurnigiensis is the most effective and playing important roles as dominant bacteria in biotechnological applications as well as industrial processes and products. Exploration of this bacterium holds great promise because of the role of microbes in nutrient cycling, environmental detoxification and novel metabolic abilities in pharmaceuticals and industrial processes and act as a major resource for agricultural, industrial, and medicinal applications
\end{abstract}

Methods: The researcher searched the PubMed database and other different Journals Online archives from September 2018 to February 2019 using the search term 'bioprospecting potential of the bacterium' to find articles published recently onwards.

Results: We included 36 published articles in our analysis. Most articles were on occurrence, diversity, insecticidal activity, metabolism, metabolic role, and industrial uses of bacterial and also economic uses of the bacterium. Members of Bacillus and related genera are used for the synthesis of a very wide range of important medical, agricultural, pharmaceutical and other industrial products.

Conclusion: With recent advances in biotechnology, the economic contributions that these organisms can make in biotechnological applications and industrial processes can be exploited further for large scale benefit of mankind.

Keywords: Bacillus thurnigiensis, Bioprospecting, Wolaita.

\section{INTRODUCTION}

Microbial diversity is a major resource for biotechnological products and processes. Exploration of microbial diversity holds great promise because of the role of microbes in nutrient cycling, environmental detoxification and novel metabolic abilities in pharmaceuticals and industrial processes and act as a major resource for agricultural, industrial, and medicinal applications (Handelsman et al., 1998). Bacteria are the most dominant group of this diversity which exists in diverse ecological niches, including extreme environments present in both lithosphere and hydrosphere, where their metabolic abilities play a critical role in geochemical nutrient cycling and producing a wide range of products of industrial significance (Daniel, 2005).

The gram-positive bacteria form an important part of the microbiota in many soils. In particular, the low $\mathrm{G}+\mathrm{C}$ content gram-positive bacteria, which are divided into three classes such as clostridia, mollicutes, and bacilli, play major roles in the mineralization of plant-derived materials, humus, pesticides and hydrocarbons in soil (Prescott et al., 2002). Members of Bacillus and related genera are used for the synthesis of a very wide range of important medical, agricultural, pharmaceutical and other industrial products. These include a variety of antibiotics, enzymes, amino acids and sugars (Probanzaet al., 2002). They are major elements of the agronomic environment of plants, inhabiting the soil. Several reports have described the biodiversity, antibiotic production and plant growthpromoting effects of Bacillus and related genera.

The purpose of this review paper is to introduce the potential of Bacillusthuringiensisisolate indigenous from Ethiopian ecology as a natural product in a soil of economic, environmental, industrial, agricultural etc. importance and to summarize the current status and developmental trends of biological control based on the published reports. 


\subsection{Taxonomy of Bacillus Thurnigiensis}

Bacillus thuringiensis was first described by Berliner when he isolated a Bacillus species from the Mediterranean flour moth, Anagastakuehniella, and named it after the province Thuringia in Germany where the infected moth was found. Although this was the first description under the name B. thuringiensis, it was not the first isolation. In 1901, a Japanese biologist, IshiwataShigetane, discovered a previously un described bacterium as the causative agent of a disease afflicting silkworms. Bt was originally considered a risk for silkworm rearing but it has become the heart of microbial insect control. The earliest commercial production began in France in 1938, under the name Sporeine (Lambert, B. and M. Peferoen. 1992). A resurgence of interest in Bt has been attributed to Edward Steinhaus, who obtained a culture in 1942 and attracted attention to the potential of $\mathrm{Bt}$ through his subsequent studies. In 1956, T. Angus demonstrated that the crystalline protein inclusions formed in the course of sporulation were responsible for the insecticidal action of Bt. By the early 1980's, Gonzalez et al.,1982 revealed that the genes coding for crystal proteins were localized on transmissible plasmids, using a plasmid curing technique, and Schnepf and Whiteley (Schnepf, H. E. and H. R. Whiteley. 1981) first cloned and characterized the genes coding for crystal proteins that had toxicity to larvae of the tobacco hornworm, from plasmid DNA of Bt subsp. kurstaki HD-1. This first cloning was followed quickly by the cloning of many other cry genes and eventually led to the development of Bt transgenic plants. In the 1980s, several scientists successively demonstrated that plants can be genetically engineered, and finally, Bt cotton reached the market in 1996 (Tabashniket al., 2005).It is classified under Eubacteria (kingdom); Bacteria (domain); Firmicutes (phylum); Bacilli (class); Bacillales (order); Bacillaceae (family); Bacillus (genus); Bacillus cereus group; Bacillus thurnigiensis (species).Bacillus thurnigiensis is a gram positive, rod-shaped, spore forming bacterium which often has insecticidal properties. $B t$ belongs to the Bacillus cereus complex which also includes B. cereus, B. anthracis and B. mycoides. The taxonomic relationships between members of the $B$. cereus group are not clear (Drobniewski 1994) and the cause of some concern as the differences between $B$. cereus and B. thurnigiensis are small and may be mainly plasmid based. DNA sequencing studies of conserved gene regions have suggested they may be strains of a single species. During sporulation in $B$. thurnigiensis, some strains produce one or more inclusions or parasporal bodies within a sporangium. The parasporal body is often toxic to specific insect groups and many different insecticidal crystal proteins ( $\delta$-endotoxins) can be found in different $B$. thurnigiensis subspecies and strains.

Many studies indicate and consider $B$. thuringiensis and $B$. cereus to be one species. However, their phenotypes greatly differ in that $B t$ produces crystal proteins despite the fact that crystal protein synthesis is controlled by plasmid genes which can be susceptible to loss and transmission to related bacteria. One response is that $B t$ strains produce enterotoxins (toxins released by micro-organisms in the lower intestine) that are involved in B. cereus pathogenesis and therefore signifies a fine-line between the two species (Cherifet al., 2007).

\subsection{Distribution of Bacillus Thurnigiensis in Ethiopian Soils}

The distribution of Bacillus thurnigiensis all over the agro-ecological zones in all soils of Ethiopia(ZelekeWoldeTenssay and MogessieAshenafi, 2008).Ethiopia's diverse climatic and agroecological conditions may also favor rich diversity of microbial flora. But, the hitherto studies on larvicidal activity of indigenous Bt against disease vectors are limited (AkliluSeyoum and Dawit Abate, 1997). The efficacy of standard B. thuringiensis subspecies kurstaki on Ethiopian crop pests was reviewed by Tsedeke Abate (1997). However, a thorough knowledge of the ecological distribution and diversity of $\mathrm{Bt}$ would have a substantial contribution to evaluate their exact role in the environment and their effects on non-target organisms. It also helps to choose appropriate soil types and insect habitats to isolate novel Bt strains. The frequency of Bt was highest in tepid to cool semiarid lakes and rift valley soils followed by cold to very cold sub-humid afroalpine and hot to warm per humid low lands. Subhumidafroalpine is characterized by limited plant species due to its cold temperature whereas the other two zones are characterized by moderate to rich fertility, which may be associated with several factors such as soil nutrients and physical and biological components important in spore germination and recycling of B. thurnigiensis. Bacillusthurnigiensis was least frequent in soil samples collected from hot to warm sub-moist mid highlands and hot to warm moist lowlands. Several workers (Hossainet al., 1997; Nicholson, 2002) have suggested that variation in abundance and distribution of B. thurnigiensis in the soils of different sources might be due to several 
ecological factors that affect the viability of B. thurnigiensis spores and recycling of B. thurnigiensis either by growth at the expense of nutrient present in the environment, or, to some extent, by association with diversity of insect types which may be distributed in those agro-ecological zones. Soil samples from the natural vegetation yielded B. thurnigiensis in a comparable rate to soils of cultivated fields. Soil samples collected from vegetable fields had lowest B. thurnigiensis yield. It is generally known that the number and types of microorganisms in soil vary depending on the type of plant cover. Naturally, insect pest distribution also differs with vegetation cover (Janzen, 1973; Bianchi et al., 2006), and if B. thurnigiensisdistribution has any correlation to crop pest distributions, it is apparent that its distribution and abundance will differ with vegetation types of the soil.

\subsection{Occurrence and Role in the Environment}

An understanding of the ecology of Bacillusthurnigiensis in the environment is essential in assessment of its environmental risk. While originally recovered mainly from insects, improved isolation and identification techniques have indicated that Bt may be ubiquitous in soil (Martin and Travers 1989). The lowest percentage recovery of Bt from soil reported was in the USA (60\% of soils sampled) (Meadows 1993). In New Zealand, (Chilcott and Wigley1993) found that between 60-100\% of soils sampled contained Bt, depending on source (urban, horticulture etc.). Bt is also indigenous in many other environments, being found in stored products, dust, on deciduous and coniferous plants and in aquatic environments. Bt has also been isolated from insect habitats such as rotting wood, wasp nests and stored products.

There are several theories on the ecological niche filled by Bt. Unlike most insect pathogenic microbes, Bts generally recycle poorly and rarely cause natural epizootics in insects, leading to speculation that Bt is essentially a soil micro-organism that possesses incidental insecticidal activity (Martin and Travers 1989). Evidence to support this view is that Bts are commonly reported in the environment independent of insects and there is a lack of association between occurrence and insect activity (van Frankenhuyzen 1993). Meadows (1993) suggested four possible explanations for the presence of $\mathrm{Bt}$ in soil: 1) rarely grows in soil but is deposited there by insects; 2) may be infective to soil-dwelling insects (as yet undiscovered); 3) may grow in soil when nutrients are available; and 4) an affinity with B. cereus. Alternatively, Smith and Couche (1991) proposed that Bt is a natural component of the phylloplanemicro flora and has evolved in a symbiotic or mutualistic association with plants to provide protection.

\section{ECONOMIC IMPORTANCE OF BACILLUS THURNIGIENSIS}

\subsection{Plant Growth Promoting Agents}

Microbial production of secondary metabolites that can promote or constrain plant growth has often been found to be finely tuned, controlled by environmental conditions, medium components, and influenced by root activities. Plant-stimulatory effects exerted by plant growth-promoting bacteria (PGPB) might also be due to an enhanced availability of limited plant nutrients such as nitrogen, phosphorus, vitamins and amino acids in the rhizosphere, caused by phosphate-solubilizing and diazotrophic bacteria (Rozycki, 1999). Bacillus is the most abundant genus in the rhizosphere, and the PGP activity of some of these strains has been known for many years, resulting in a broad knowledge of the mechanisms involved (Probanzaet al., 2002).

\subsection{Persistence and Activity in the Environment}

Bacillus thuringiensis is the most common environmentally-friendly insecticide used and is the basis of over $90 \%$ of the pesticides available in the market today (Cherifet al., 2007). Having sequenced the entire genome, scientists can witness and determine how mutations can create different variant strains that may eventually grow stronger against agricultural pests. Bacillus thurnigiensishas many properties which make it a superior mosquito control agent; for example it is environmentally benign, easily produced and host specific. One characteristic which contributes to a lack of environmental risk is lack of persistence. Generally, Bt persists for days rather than months as reported for some of the more toxic chemicals for mosquito control. Early reports showed that a primary powder formulation of $\mathrm{Bt}$ (serotype $\mathrm{H}-14$ ) had virtually no residual effect against mosquito larvae beyond application, although the delta-endotoxin remained chemically stable in neutral and acid waters (Sinegreet al. 1980). 


\subsection{As Biotechnological Agents in Industrial Processes and Production}

Bacillus thuringiensis produces the Cry crystal toxin that attacks the gut of pests and kills them internally. These Cry toxins are good agricultural tools for growing plants. Instead of using chemicals that may have adverse effects on humans, genetic engineers integrate the $B t$ toxin into the plant's genome. These $B t$ Cry toxins are safe for humans and kill off species of pests that are susceptible to the Bacillus thuringiensis endospore. Each single strain of organism produces a large number of enzymes which include the function such as hydrolyzing, oxidizing or reducing, and metabolic in nature. But the absolute and relative amounts of the various individual enzymes produced vary markedly between species and even between strains of the same species. Amylase, lipase, protease and cellulase constitute a very important part of microbial enzymes that are used in food, pharmaceutical, textile, paper, leather, and other industries. It is estimated that Bacillus spp. enzymes make up about $50 \%$ of the total enzyme market (Schallmeyet al., 2004).

Food fermentations mediated by Bacillus, can provide insight into some of the potential industrial properties of the genera or species involved. Recent developments in genetic engineering and fermentation technology have contributed to improvements in D-ribose productivity by Bacillus fermentations. Most members of the genus Bacillus are able to produce antibiotics. Interestingly, the majority of these antibiotics are low-molecular-weight peptides, which possess different biological activities, including antimicrobial, antiviral, and antitumor activities (Giacomodonatoet al., 2001).

\subsection{Bacillus Thurnigiensisas Insecticidal Agents}

Global use of insecticides for mosquito vector control in recent decades has caused environmental pollution of aqueous ecosystem and resulted in insecticide resistance in many mosquito species. The last decade has witnessed and increased interest in biological control agents. Biological means to control vectors, based on entomopathogenic bacteria has been studied for more than 20 years. More number of biological control agents was screened for their efficacy, mammalian safety and environmental impact. Many organisms have been investigated as potential agents for vector mosquito control, including viruses, fungi, bacteria, protozoa, nematodes, invertebrate predators and fish (ZulfaidahP. and Nobukazu N. 2014). Only a few spore forming bacteria, copepods and fish have reached operational use and are undergoing extensive field trials. The discovery of bacteria like $B$. thuringiensisserovarisraelensisdeBarjac, which are highly toxic to dipteran larvae have opened up the possibility of its use aspotentialbiolarvicides in mosquito eradication programs in the over the world (Poopathi and Tyagi, 2002; Poopathi et al.,2002). The larvicidal substances of these preparations are based on endotoxin proteins accumulated as parasporal crystals produced by the bacterial cells during the sporulation growth phase. These biological preparations have some important advantages over conventional insecticides in mosquito control operations, besides being safe to nontarget organism including human beings. Also, it is harmless to the environment (Prabakaran and Balaraman, 2006). The B.thuringiensisserovarisraelensishas been used operationally for the control of mosquitoes for over two decades and its formulations are highly effective against Anopheles, Aedesand Culexmosquitoes (Poopathi and Abidha,2010).

\section{Host RANGE}

Bacillus thurnigiensis is highly pathogenic against Culicidae (mosquitoes) and Simuliidae (blackflies), and has some virulence against certain other Diptera, especially Chironomidae (midges). There are few records of susceptibility outside these dipteran groups, and most other hosts within Diptera require high doses to kill. Bt is generally regarded as specific to larvae of the Nematocera, which include filter-feeding mosquitoes and Simulium (blackflies, sandflies) (Clarke,1994). However, the vast majority of susceptible hosts are recorded in nematocerous Diptera. Among mosquitoes, different preparations of Bt have shown differing levels of toxicity to host species. Generally, Culex and Aedesare highly susceptible while Anopheles are less susceptible, but can still be killed with Bt (Balaramanet al., 1983). However, even within one genus, some species are more susceptible than others (Chui et al., 1993). 


\section{Future Prospects Of BaCILlus Thurnigiensis}

The use of Bt spray as an insecticide has several disadvantages; 1) Bt spray cannot be applied uniformly to all parts of the plant, 2) it cannot be delivered to pests that are inside plant tissues, and 3) $\mathrm{Bt}$ is susceptible to rapid degradation by UV light and removal by water runoff. Therefore, multiple applications are required to provide extended pest protection (Schnepfet al.,1998). Moreover, since McGaugheyreported resistance to $\mathrm{Bt}$ in Indian meal moth populations(Gonzalez et al.,1982) resistance to Bt sprays has also evolved in greenhouse populations of the cabbage looper and in field populations of the diamondback moth (Tabashnik, B. E. 1994). Transgenic crops with Bt cry genes might overcome these kinds of disadvantages.

This feature eliminates difficulties in targeting pests that burrow into plant tissues, as well as the labor and expenses associated with applying sprays. At present, field-evolved resistance to Bt crops has not been documented. (Tabashniket al., 2005) reported long-term resistance levels in transgenic Bt crop fields. Generally, it has been a concern that an increase in the wide planting of Bt crops might lead to rapid evolution of resistance to Bt toxins by pests (Tabashnik, B. E. 1994).

However, bioassay results show no net increase from 1997 to 2004 in the mean frequency of pink bollworm resistance to Bt toxin (Tabashniket al., 2005). This delay in resistance can be explained by the presence of refuges of cotton without $\mathrm{Bt}$ toxin, recessive inheritance of resistance, incomplete resistance, and fitness costs associated with resistance.

Basically, the advantages of Bt and Bt crops apparently includes 1) no harmful effects on vertebrates and humans, or the ecological environment, 2) low impacts on non target organisms, and 3) a narrow spectrum of primarily leaf-feeding lepidopteran targets. These merits, including the short field life of the spray, are still this biopesticide's greatest challenge in the pesticide market (Whalon, M. E. and B. A. Wingerd. 2003). For the sustainable use of $\mathrm{Bt}$, it is imperative that there be 1) collections of $\mathrm{Bt}$ isolates, crystal proteins, and strains of related species, 2) investigations into the persistence of crystal proteins and possible long-term effects on non target organisms and the environment, 3) development of improved resistance management strategies, and 4)genetic engineering of Bt genes into the plastid genomes of transgenic crops (Nester et al., 2002). Environmentally safe-insect control strategies based on the Bts and their insecticidal crystal proteins are going to increase in the future, especially with the wide adoption of transgenic crops. In conclusion, the discovery of new toxins and new ways of presenting the toxin to the target insects, which includes the development of recombinant microorganisms and proteomic technology, could be adapted to the study of Bt crystal proteins; additionally, interaction studies between Bt and target insects involving modes of action of Bt Cry proteins and resistance mechanisms should be carried out, all of which are fundamental studies that will allow for improvement of existing Bt application strategies and the ability to design alternative options.

\section{CONCLUSION}

According to the studies cited in different literatures Bacillus thurnigiensisis reported as the most effective and playing important roles as dominant bacteria in biotechnological applications as well as industrial processes and products. And, with recent advances in biotechnology, the economic contributions that these organisms can make in biotechnological applications and industrial processes can be exploited further for large scale benefit of mankind. Therefore, Ethiopian Biodiversity Institute Microbial Directorate collected, isolated and identified several Bacillusspp. And Bacillus thurnigiensis is one of them collected across the country. There are number of potential Bacillus species in the gene bank of the institute. One of the major Bacillus species are Bacillus thuringiensis. Therefore, we encourage any bio prospecting company to access this genetic resource for its potentials in biotechnological applications as well as industrial processes and products for access and benefit sharing.

\section{ACKNOWLEDGEMENT}

The author would like to express deepest gratitude to Yishak Abraham for his advices, sharing his knowledge by reading and editing the manuscript. The author extends gratitude to Wolaita Soddo University College of Natural and Computational Science Department of Biology staff members for their technical \& material support. 


\section{REFERENCES}

[1] AkliluSeyoum and Dawit Abate (1997). Larvicidal efficacy of B. thuringiensisvarisraelensis and B. sphaericus on Anophelesearabiensis in Ethiopia. World J. Microbiol. Biotechnol. 13: 21-24.

[2] Balaraman, K., Balasubramanian, M. \&Manonmani L.M. (1983). Bacillus thuringiensis H-14 (VCRC B17) formulation as mosquito larvicide. Indian Journal of Medical Research 77, 33-37.

[3] Bianchi, F.J.J. A., Booij, C.J.H. and Tscharntke (2006). Sustainable regulation in agricultural landscapes: A review on landscapes composition, biodiversity and natural pest control. Proceeding R. Soc. B. 273: 1715-1727.

[4] Cherif, A., Ettoumi, B., Raddadi, N., Daffonchio, D., Boudabous, A. (2007)."Genomic diversity and relationship of Bacillus thuringiensis and Bacillus cereus by multi-REP-PCR fingerprinting". Canadian Journal of Microbiology. Volume 53. p. 343-350

[5] Chilcott, C. N. \&Wigley, P. J. (1993). Isolation and toxicity of Bacillus thuringiensis from soil and insect habitats in New Zealand. Journal of Invertebrate Pathology 61, 244-247.

[6] Chui, V. W. D., Koo, C. W., Lo, W. M., Qiu, X. \&Qiu, X. J. (1993). Laboratory evaluation of Vectobac12AS and teflubenzuron against Culex and Aedes mosquito larvae under different physical conditions. Environment International 19, 193-202.

[7] Clarke, G. R. (1994). Bacillus thuringiensis var. israelensis in mosquito control. In Proceedings of the 1st Brisbane Symposium Biopesticides: opportunities for Australian Industry (ed. C.J. Monsour, S. Reid \& R.E. Teakle), Brisbane, pp. 87-90.

[8] Daniel R, The metagenomics of soil, Nat Rev Microbiol, 3 (2005) 470-478.

[9] Drobniewski, F. A. (1994). The safety of Bacillus species as insect vector control agents. Journal of Applied Bacteriology 76, 101-109.

[10] Giacomodonato M N, Pettinari M J, Guadalupe I S, Beatriz S M \& Lopez N I, A PCR-basedmethod for the screening of bacterial strains with antifungal activity in suppressive soybeanrhizosphere, World $J$ MicrobiolBiotechnol, 17 (2001) 51-55.

[11] Gonzalez, J. M. Jr., B. J. Brown, and B. C. Carlton. 1982.Transfer of Bacillus thuringiensis plasmids coding for $\delta$-endotoxin among strains of B. thuringiensis and B. cereus. Proc. Natl. Acad. Sci. USA 79: 6951-6955.

[12] Handelsman J, Rondon M R, Brady S F, Clardy J \& Goodman R M, Molecular biological accessto the chemistry of unknown soil microbes: a new frontier for natural products, ChemBiol, 5(1998) 245-249.

[13] Hossain, M.A., Ahmed, S. and Hoque, S. (1997). Abundance and distribution of B. thuringiensis in the agricultural soil of Bangladesh. J. Invertebr. Pathol70: 221-225.

[14] Janzen, D. H. (1973). Sweep samples of tropical foliage insects: effects of seasons, vegetation types, elevation, time of dry and insularity. Ecology 54: 687-708.

[15] Lambert, B. and M. Peferoen. 1992. Insecticidal promise of Bacillus thuringiensis. Facts and mysteries about a successful biopesticide.BioScience 42: 112-122.

[16] Martin, P. A. W. \& Travers, R. S. (1989). Worldwide abundance and distribution of Bacillus thuringiensis isolates. Appl. Environ. Microbiol. 55, 2437-2442.

[17] Meadows, M. P. (1993). Bacillus thuringiensis in the environment: ecology and risk assessment. In Bacillus thuringiensis, an Environmental Biopesticide: Theory and Practice (ed. P. F. Entwistle, J. S. Cory, M. J. Bailey and S. Higgs). Pp. 193-220. John Wiley \& Sons.

[18] Nester, E. W., L. S. Thomashow, M. Metz, and M. Gordon. 2002. 100 Years of Bacillus thuringiensis: A Critical Scientific Assessment. American Academy of Microbiology.

[19] Poopathi, S. and Abidha, S. 2010. Mosquitocidal bacterial toxins (Bacillus sphaericus and Bacillus thuringiensis serovar israelensis): Mode of action, cytopathological effects and mechanism ofresistance. Journal of Physiology and Pathophysiology 1(3), 22-38.

[20] Poopathi, S. and Tyagi, B.K. 2002. Studies on Bacillus sphaericus toxicity-related resistance development and biology in the filariasis vector, Culex quinque fasciatus (Diptera: Culicidae) from South India. Applied Entomological Zoology 37(3), 365-371.

[21] Poopathi, S. and Tyagi, B.K. 2006. The challenge of mosquito control strategies: from primordial to molecular approaches. Journal Biotechnology and MolecularBiology Review 1(2), 51-65.

[22] Prabakaran, G. and K. Balaraman 2006.Development of a cost-effective medium for the large scale production of Bacillus thuringiensis var. israelensis. Biological control 36, 288-292.

[23] Prescott L M, Harley J P \& Klein DA (2002) Microbiology, $5^{\text {th }}$ ed, McGraw-Hill, New York.

International Journal of Research Studies in Microbiology and Biotechnology (IJRSMB) 
[24] Probanza A, Lucas García J A, Ruiz Palomino M, Ramos B \& Gutiérrez Mañero FJ, PinuspineaLseedling growth and bacterial rhizosphere structure after inoculation with PGPR Bacillus (B. licheniformisCECT 5106 and B. pumilusCECT 5105),Appl Soil Ecol, 20 (2002) 75-84.

[25] Rozycki H, Dahm H, Strzelczyk E \& Li C Y, Diazotrophic bacteria in root-free soil and in theroot zone of pine (Pinussylvestris L.) and oak (Quercusrobur L.), Appl Soil Ecol, 12 (1999) 239-250.

[26] Schallmey M, Singh A \& Ward O P, Development in the use of Bacillus species for industrialproduction, Can J Microbiol, 50 (2004) 1-17.

[27] Schnepf, E., N. Crickmore, J. Van Rie, D. Lereclus, J. Baum, J. Feitelson, D. R. Zeigler, and D. H. Dean. 1998. Bacillus thuringiensis and its pesticidal crystal proteins. Microbiol. Mol. Biol. Rev. 62: 775-806.

[28] Schnepf, H. E. and H. R. Whiteley. 1981. Cloning and expression of the Bacillus thuringiensis crystal protein gene in Escherichia coli. Proc. Natl. Acad. Sci. USA 78: 2893-2897.

[29] Sinegre, G. (1980). Contribution to the normalisation of laboratory trials concerning experimental and commercial formulations of serotype $\mathrm{H}-14$ of Bacillus thuringiensis I. Stability of test suspensions and detection of possible toxic chemical contaminants for mosquito larvae. WHO, Geneva. 6pp. Unpublished.

[30] Shelton, A. M., J. Z. Zhao, and R. T. Roush. 2002. Economic, ecological, food safety, and social consequences of the deployment of Bt transgenic plants. Annu. Rev.Entomol. 47: 845-881.

[31] Smith, R. A. \&Couche, G. A. (1991). The phylloplane as a source of Bacillus thuringiensis variants. Applied and Environmental Microbiology 57, 311

[32] Tabashnik, B. E. 1994. Evolution of resistance to Bacillus thuringiensis. Annu. Rev. Entomol. 39 : 47-79.

[33] Tabashnik, B. E., T. J. Dennehy, and Y. Carriere. 2005. Delayed resistance to transgenic cotton in pink bollworm. Proc. Natl. Acad. Sci. USA 102: 15389-15393.

[34] Whalon, M. E. and B. A. Wingerd. 2003. Bt: Mode of action and use. Arch. Insect Biochem. Physiol. 54: 200-211.

[35] Zeleke W/Tenssay and MogessieAshenafi (2008). Frequency and Distribution of Bacillus thuringiensis from Ethiopian soils. Ethiop. J. Biol. Sci., 7(1): 55-67.

[36] ZulfaidahP.andNobukazu N. 2014. Safe Strategy to Control Mosquito: The Potential of Bacillus thuringiensisIsolated Indigenously from East Java as a Natural Agentsof Mosquito: Aedesaegypti. Int.J.Curr.Microbiol.App.Sci.3(2): 179-197

Citation: Asfaw Tora Kacho," Economic Importance of Bacillus Thurnigiens is bacterium for Bio Prospecting: A Review ", International Journal of Research Studies in Microbiology and Biotechnology (IJRSMB), vol. 5, no. 2, pp. 1-7, 2019. Available: DOI: http://dx.doi.org/10.20431/2454-9428.0502001

Copyright: (C) 2019 Authors. This is an open-access article distributed under the terms of the Creative Commons Attribution License, which permits unrestricted use, distribution, and reproduction in any medium, provided the original author and source are credited. 